\title{
Natural Anaplasma phagocytophilum infection in ticks from a forest area of Selenge province, Mongolia
}

\author{
Javkhlan $G,{ }^{a}$ Enkhtaivan $B,{ }^{a}$ Baigal $B, b$ Myagmarsuren $P, a$ Battur $B^{a}$ and Battsetseg $B^{a}$ \\ Correspondence to Battsetseg Badgar (e-mail: bata07@gmail.com).
}

Anaplasma phagocytophilum is a zoonotic agent of public health importance, infecting both humans and animals. An investigation of the presence of Anaplasma phagocytophilum as well as Anaplasma platys was conducted in a forest area of Selenge province, Mongolia, where ticks are widely distributed and tick-borne diseases are highly endemic. Ticks were collected and tested using polymerase chain reaction based on groEL methodology. Anaplasma phagocytophilum was detected in 14 (6\%) of Ixodes persulcatus ticks and four (1\%) Dermacentor nuttalli ticks; infection of Anaplasma platys was detected in $1 \%$ of Ixodes persulcatus ticks and $10 \%$ of Dermacentor nuttalli ticks. The phylogenetic tree showed that the Anaplasma phagocytophilum clustered with the Russian group, most likely due to similar geographical locations. This finding is significant for both veterinary and public health officials given that these agents can cause both animal and human illness.

A naplasma phagocytophilum is a gramnegative obligate intracellular bacterium long recognized as a veterinary agent ${ }^{1}$ and more recently as a human infection. Human granulocytic anaplasmosis (HGA) was first reported in the United States of America in $1994,{ }^{2}$ and since then Anaplasma phagocytophilum has been considered an emerging pathogen of public health importance. ${ }^{3}$ HGA is characterized by headache; chill; myalgia; arthralgia; malaise; and hematological abnormalities such as thrombocytopenia, leukopenia and elevated hepatic aminotransferase levels. ${ }^{4}$ Anaplasma phagocytophilum is thought to be naturally maintained in a tick-rodent cycle with humans being involved only as incidental dead-end hosts. ${ }^{5}$

In Mongolia, livestock play an important role as reservoirs of Anaplasma phagocytophilum in endemic areas. The first study on human seroprevalence against Anaplasma phagocytophilum for central Asia reported a seroprevalence of $2.3 \%$ in Selenge province, $5.6 \%$ in Bulgan province, $2.8 \%$ in Dornogov province and $3.0 \%$ in both Tov province and Ulaanbaatar. ${ }^{6}$

The objective of this study was to investigate the presence of Anaplasma phagocytophilumin tick vectors in a forest area of Selenge province, Mongolia.

\section{METHODS}

Un-engorged ticks were collected from two districts in Selenge province, Mongolia, Altanbulag and Khuder, both which border the Russian Federation. These districts were chosen for the study as they contain forest areas where ticks are widespread. Ticks were identified to the species level and stored alive at $4{ }^{\circ} \mathrm{C}$ until used. Tick samples (3-5 ticks) were frozen and mashed by liquid nitrogen and then deoxyribonucleic acid (DNA) was extracted using the G-spin genomic DNA extraction kit (iNrRON Biotechnology Inc., Republic of Korea).

Polymerase chain reaction (PCR) was conducted using groEL PCR-restriction fragment length polymorphism and sequence analysis. ${ }^{7}$ Primers designed to amplify the partial groEL gene encoding heat-shock protein of Anaplasma phagocytophilum EphplgroELF (5'-ATGGTATGCAGTTTGATCGC-3') and EphplgroELR (5'-TCTACTCTGTCTTTGCGTTC-3') were used and expected to yield a 625-bp product for Anaplasma phagocytophilum and for Anaplasma platys, respectively. PCR amplifications were performed using the Maxime PCR PreMix kit (iNrRON Biotechnology Inc., Republic of Korea). All PCR products were separated by agarose gel electrophoresis, stained with

\footnotetext{
Laboratory of Molecular Genetics, Institute of Veterinary Medicine, Mongolian State University of Agriculture, Ulaanbaatar, Mongolia. Laboratory of Virology, National Center for Zoonotic Diseases, Ulaanbaatar, Mongolia.

Submitted: 26 July 2013; Published: 5 March 2014

doi: 10.5365/wpsar.2013.4.3.001
} 
Figure 1. Phylogenetic tree of Anaplasma phagocytophilum groEL gene

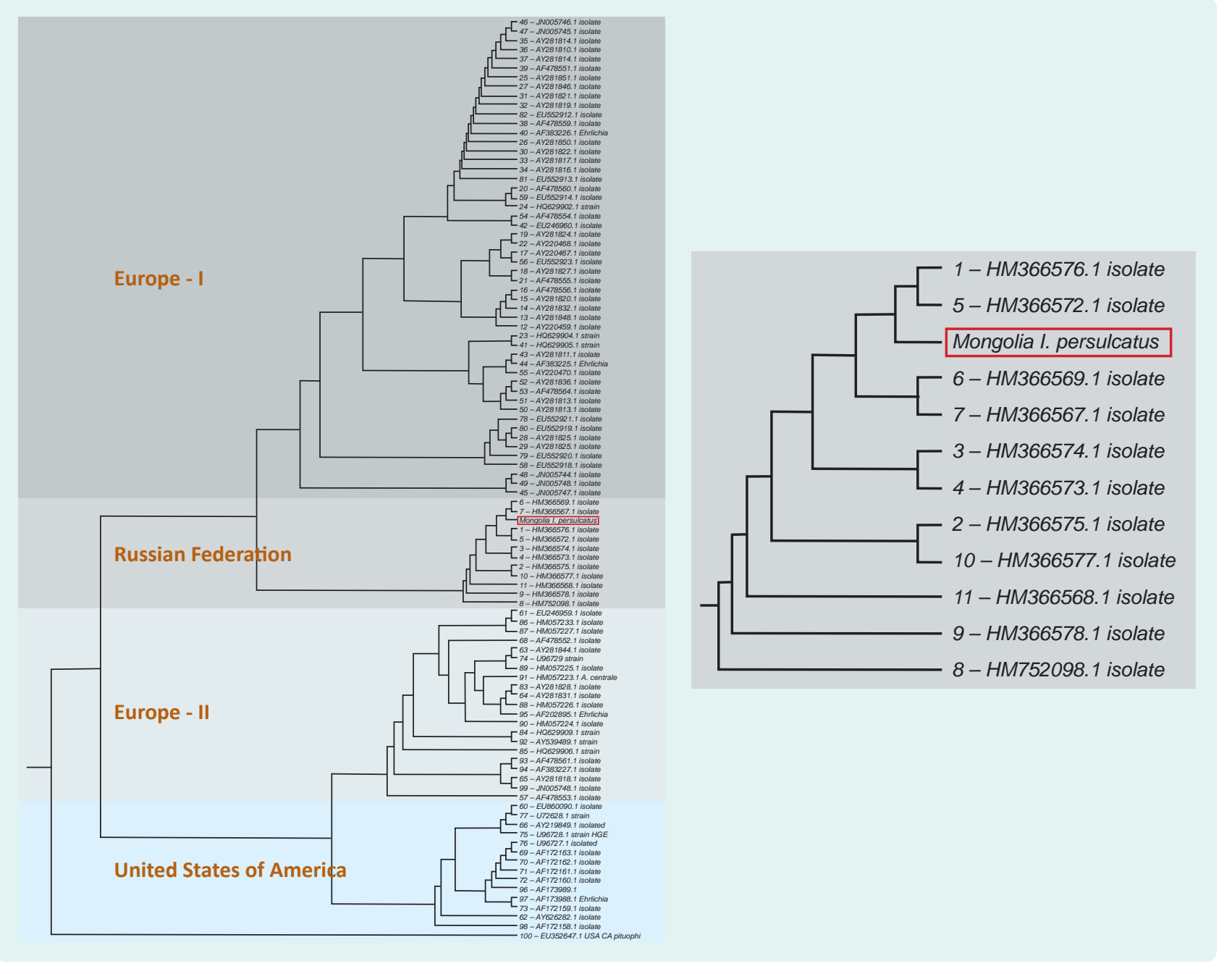

ethidium bromide and visualized under ultraviolet light (Figure 1).

Direct DNA sequencing was performed using the same PCR primers. If the sequence result was of low quality, the amplicon was cloned into a plasmid vector using a TOPO TA cloning kit (Invitrogen, Carlsbad, California) and then sequenced using the primers provided with the kit. Nucleotide sequences were initially checked using the Basic Local Alignment Search Tool hosted by the National Center for Biotechnology Information (http://blast.ncbi.nlm.nih.gov/Blast.cgim) for comparison with other known nucleotide sequences. The multiple alignment analysis and phylogenetic analysis were performed using the ClustalW online server (http://www.genome.jp/tools/clustalw/) with the default parameters.

\section{RESULTS}

A total of 242 unfed ticks, comprising 222 adult Ixodes persulcatus ticks and 20 adult Dermacentor nuttalli ticks, were collected and individually examined. Of these, 14 (6.3\%) Ixodes persulcatus samples and four (20\%) Dermacentor nuttalli samples were positive for Anaplasma phagocytophilum; four (1.8\%) Ixodes persulcatus samples and two (10\%) Dermacentor nuttalli samples were positive for Anaplasma platys (Table 1).

The phylogenetic tree showed four main clusters: Europe-I, Russian Federation, Europe-II and United States of America (USA). The Anaplasma phagocytophilum groEL gene sequences from this study clustered within the Russian group and were most 
Table 1. Detected of Anaplasma phagocytophilum and Anaplasma platys in ticks by species, district and gender, Selenge province, Mongolia, 2013

\begin{tabular}{|c|c|c|c|c|c|}
\hline Tick species & District & $\begin{array}{c}\text { Tick } \\
\text { gender }\end{array}$ & $\begin{array}{l}\text { No. of } \\
\text { samples }\end{array}$ & $\begin{array}{l}\text { Positive for Anaplasma } \\
\text { phagocytophilum (\%) }\end{array}$ & $\begin{array}{c}\text { Positive for Anaplasma } \\
\text { platys (\%) }\end{array}$ \\
\hline \multirow{7}{*}{$\begin{array}{l}\text { Dermacentor nuttalli } \\
(n=20)\end{array}$} & \multirow[t]{2}{*}{ Altanbulag } & Female & 6 & $1(16.7)$ & - \\
\hline & & Male & 4 & $1(25.0)$ & - \\
\hline & \multirow[t]{2}{*}{ Khuder } & Female & 6 & $1(16.7)$ & 2 (33.3) \\
\hline & & Male & 4 & $1(25.0)$ & - \\
\hline & \multirow[t]{3}{*}{ Subtotal } & Female & 12 & 2 (16.7) & $2(16.7)$ \\
\hline & & Male & 8 & $2(25.0)$ & - \\
\hline & & All & 20 & $4(20.0)$ & $2(10.0)$ \\
\hline \multirow{8}{*}{$\begin{array}{l}\text { Ixodes persulcatus } \\
(n=222)\end{array}$} & \multirow[t]{2}{*}{ Altanbulag } & Female & 23 & $3(13.0)$ & $1(4.4)$ \\
\hline & & Male & 26 & $2(7.7)$ & $1(3.8)$ \\
\hline & \multirow[t]{2}{*}{ Khuder } & Female & 88 & $5(5.7)$ & $2(2.3)$ \\
\hline & & Male & 77 & $4(5.2)$ & - \\
\hline & Unknown & & 8 & - & - \\
\hline & \multirow[t]{3}{*}{ Subtotal } & Female & 111 & $8(7.2)$ & $3(2.7)$ \\
\hline & & Male & 103 & $6(5.8)$ & $1(1.0)$ \\
\hline & & All & 222 & $14(6.3)$ & $4(1.8)$ \\
\hline Total & & & 242 & $18(7.4)$ & $6(2.5)$ \\
\hline
\end{tabular}

closely related to the Anaplasma phagocytophilum detected in Ixodes persulcatus ticks from Novosibirsk (GenBank:HM366569.1) and from Sverdlovsk (GenBank:HM366567.1) in the Russian Federation and were genetically distinct from Anaplasma phagocytophilum agents found in Europe-I, Europe-II and USA groups (Figure 1).

\section{DISCUSSION}

Discrepant infection of Anaplasma phagocytophilum in ticks has been observed around the world. In this study, both Anaplasma phagocytophilum and Anaplasma platys infection were detected in ticks from the forest area of Selenge province, Mongolia. For Ixodes persulcatus ticks the prevalence of Anaplasma phagocytophilum was $6.3 \%$, similar to the $4.6 \%$ reported in a previous study from Inner Mongolia Autonomous Region and Heilongjiang Province, China. ${ }^{8}$ Infection in female Ixodes persulcatus ticks was higher than in males. Anaplasma platys infection in Ixodes persulcatus ticks was $1.8 \%$. For Dermacentor nuttalli ticks, Anaplasma phagocytophilum was detected in $20 \%$ and Anaplasma platys in $10 \%$. This suggests that these tick species may play a role in the transmission of both Anaplasma phagocytophilum and Anaplasma platys from ticks to humans in nature.
The phylogenetic tree showed clustering within the Russian group most closely with other samples from the same tick species from the Russian Federation and genetically distinct from agents found in Ixodes ricinus ticks, ruminants, horses, humans and more. As Selenge province is located in the north part of Mongolia and borders the Russian Federation, it has a similar geographical topography and therefore this result is not surprising. Ixodes persulcatus is the vector of Anaplasma phagocytophilum in Asia, the Ural Mountains in the Russian Federation, Siberia, the Far East and in the Russian Baltic region. ${ }^{9}$ /xodes persulcatus is distributed within the north and north-eastern parts of Mongolia; Dermacentor nuttalli is more widely distributed throughout Mongolia.

To the author's knowledge, this study is the first description of Anaplasma phagocytophilum and Anaplasma platys in ticks in Mongolia and has both veterinary and public health significance given that these agents can cause both animal and human illness. As there is already serological evidence of human illness from Anaplasma phagocytophilum in Mongolia, ${ }^{6}$ an understanding of the transmission mechanisms from tick to humans is required to develop prevention methods for HGA. 


\section{Conflicts of interest}

None declared.

Funding

None.

\section{References:}

1. Dumler JS et al. Reorganization of genera in the families Rickettsiaceae and Anaplasmataceae in the order Rickettsiales: unification of some species of Ehrlichia with Anaplasma, Cowdria with Ehrlichia and Ehrlichia with Neorickettsia, descriptions of six new species combinations and designation of Ehrlichiaequi and 'HGE agent' as subjective synonyms of Ehrlichiaphagocytophila. International Journal of Systematic and Evolutionary Microbiology, 2001, 51:2145-2165. doi:10.1099/0020771351-6-2145 pmid:11760958

2. Chen $\mathrm{SM}$ et al. Identification of a granulocytotropic Ehrlichia species as the etiologic agent of human disease. Journal of Clinical Microbiology, 1994, 32:589-595. pmid:8195363

3. Walker DH, Dumler JS. Emergence of the ehrlichioses as human health problems. Emerging Infectious Diseases, 1996, 2:18-29. doi:10.3201/eid0201.960102 pmid:8903194
4. Bakken JS et al. Clinical and laboratory characteristics of human granulocytic ehrlichiosis. Journal of the American Medical Association, 1996, 275:199-205. doi:10.1001/ jama.1996.03530270039029 pmid:8604172

5. Telford SR 3rd et al. Perpetuation of the agent of human granulocytic ehrlichiosis in a deer tick-rodent cycle. Proceedings of the National Academy of Sciences of the United States of America, 1996, 93:6209-6214. doi:10.1073/pnas.93.12.6209 pmid:8650245

6. Walder $\mathrm{G}$ et al. Serological evidence for tick-borne encephalitis, borreliosis, and human granulocytic anaplasmosis in Mongolia. International Journal of Medical Microbiology, 2006, 296 Suppl 40:69-75. doi:10.1016/j.ijmm.2006.01.031 pmid: 16524782

7. Hancock SI, Breitschwerdt EB, Pitulle C. Differentiation of Ehrlichia platys and $E$. equi infections in dogs by using $16 \mathrm{~S}$ ribosomal DNA-based PCR. Journal of Clinical Microbiology, 2001 , 39:4577-4578. doi:10.1128/JCM.39.12.45774578.2001 pmid:11724889

8. Cao WC et al. Prevalence of Anaplasma phagocytophila and Borrelia burgdorferi in Ixodes persulcatus ticks from northeastern China. The American Journal of Tropical Medicine and Hygiene, 2003, 68:547-550. pmid:12812342

9. Katargina $O$ et al. Identification of Anaplasma phagocytophilum in tick populations in Estonia, the European part of Russia and Belarus. Clinical Microbiology and Infection, 2012, 18:40-46. doi:10.1111/j.1469-0691.2010.03457.x pmid:21199155 